\title{
The Case-Study of the RES-NOVAE National Project: Low-Cost Sensor-Systems for Urban Air Quality Monitoring
}

\author{
D. Suriano, M. Prato, V. Pfister, G. Cassano, S. Dipinto, M. Penza \\ Lab Functional Materials and Technologies for Sustainable Applications, ENEA, Brindisi, Italy \\ michele.penza@enea.it
}

\begin{abstract}
This paper gives a brief report on preliminary real-world measurements by low-cost gas sensorsystems for air quality monitoring in the framework of the Italian national project RES-NOVAE Networks Buidings Streets: New Challenging Objectives for Environment and Energy. Measurements were performed by low-cost electrochemical gas sensors $\left(\mathrm{CO}, \mathrm{NO}_{2}, \mathrm{O}_{3}, \mathrm{SO}_{2}\right)$, optical particle counter/detector $\left(\mathrm{PM}_{1.0}, \mathrm{PM}_{2.5}, \mathrm{PM}_{10}\right)$, NDIR infrared sensor $\left(\mathrm{CO}_{2}\right)$, photo-ionisation detector (total VOCs), including miniaturized sensors for meteorological parameters (temperature, relative humidity). The sensors are running and installed in the city of Bari (Italy) to assess the performance during a campaign of several months of operation in the framework of sustainable innovation and citizen science in the smart cities. The first results indicate that these solutions are promising for air quality monitoring to address data quality objective of Indicative Measurements (Directive 2008/50/EC) [1].
\end{abstract}

Key words: Air quality, Gas/VOCs/PM detection, Stationary/Mobile sensor-systems, Real-world measurements

\section{Introduction}

Environmental monitoring is strongly required to protect the public health [2] and save the environment from toxic contaminants and pathogens that can be released into air. Airpollutants include carbon monoxide (CO), nitrogen dioxide $\left(\mathrm{NO}_{2}\right)$, sulfur dioxide $\left(\mathrm{SO}_{2}\right)$, particulate matter (PM), that originate from various sources such as vehicle emissions, power plants, refineries, industrial and laboratory processes. Ozone $\left(\mathrm{O}_{3}\right)$ detection is a key parameter to control the urban environment. Volatile organic compounds (VOCs) are critical for environmental protection and human health as well. Greenhouse gases $\left(\mathrm{CO}_{2}, \mathrm{CH}_{4}, \mathrm{~N}_{2} \mathrm{O}\right.$, etc. $)$ are important to be monitored in order to estimate the current trend of the sustainability in the smart cities and megacities. The World Health Organization (WHO) reports the air pollution as a significant risk factor for human health. This causes serious problems such as skin and eyes infections, irritations, heart diseases, bronchitis, asthma, lung cancer. Also, air pollution is one of the major causes for many premature deaths. Finally, air pollution not only has bad effects on public health but also on the environment such as acid rains, photochemical smog, ozone layer deterioration, global warming.

However, current monitoring methods are costly and time-consuming, also limitations in sampling and analytical techniques exist. Clearly, a need exists for accurate, inexpensive long-term monitoring of environmental contaminants using low-cost solid-state gas sensors that are able to operate on-site and real-time [3-5]. Calibrated cost-effective gas sensors are a very interesting solution for networked systems suitable to monitor air-pollutants in urban streets and real scenario of smart cities with high spatial and time resolution. Stationary and mobile approaches of sensor-systems for air quality monitoring are challenging for real-time and in-situ real-world measurements [6].

Air quality (AQ) sensors need to improve accuracy, selectivity and stability to address the data quality objective (DQO) according to the recommended values by the European Directive (2008/50/EC) on Ambient Air Quality in Europe [1]. They are challenging to be detected in the range of low ppb-ppm range, depending on targeted pollutant, as shown in the Table 1.

Tab. 1: Target Values of EU Directive 2008/50/EC.

\begin{tabular}{|c|c|}
\hline Pollutant & Limit Level \\
\hline $\mathrm{NO}_{x}$ & $100 \mathrm{ppb}, 200 \mathrm{ppb}$ \\
\hline $\mathrm{CO}$ & $8 \mathrm{ppm}$ \\
\hline $\mathrm{SO}_{2}$ & $130 \mathrm{ppb}, 190 \mathrm{ppb}$ \\
\hline $\mathrm{O}_{3}$ & $120 \mu \mathrm{g} / \mathrm{m}^{3}$ \\
\hline $\mathrm{PM}_{10}$ & $50 \mu \mathrm{g} / \mathrm{m}^{3}$ \\
\hline $\mathrm{BTEX}$ & $6 \mu \mathrm{g} / \mathrm{m}^{3}$ \\
\hline $\mathrm{PAH}(\mathrm{BaP})$ & $1 \mathrm{ng} / \mathrm{m}^{3}$ \\
\hline $\mathrm{PM}_{2.5}$ & $25 \mu \mathrm{g} / \mathrm{m}^{3}$ \\
\hline
\end{tabular}




\section{The Italian project RES-NOVAE}

The Italian national project [7] RES-NOVAE Networks Buidings Streets: New Challenging Objectives for Environment and Energy - funded by Italian Ministry of University, Research and High Schools (MIUR) in the framework of PON Research \& Competitiveness Smart Cities, developed and demonstrated an integrated system of new technologies for sustainable development in the green cities (Bari and Cosenza, Italy) to improve environmental sustainability and carbon footprint to enhance energy efficiency at level of network of buildings, smart district and urban control center.

The final goal of RES-NOVAE is to implement a trust of best available technologies to improve the quality of life of citizens and support the decisions of the policy-makers and city managers in order to plan the urban development with reduced greenhouse gases emissions.

A sensor network, designed and operated by ENEA, based on 10 nodes (9 stationary and 1 mobile on public bus), for air quality monitoring has been deployed in the city of Bari for a longterm experimental campaign since June-2015 till December-2016 at least. Each multiparametric sensor node is composed by at least 9 sensing elements $\left(\mathrm{NO}_{2}, \mathrm{O}_{3}, \mathrm{CO}, \mathrm{SO}_{2}, \mathrm{PM}_{10}\right.$, tVOCs, $\mathrm{CO}_{2}$, $\mathrm{T}, \mathrm{RH}$ ) including data acquisition system and mother board (Raspberry Pi), GPS, GSM modem with standard functionalities of wireless data transmission towards a base station.

Mapping of the targeted air pollutants, expressed as individual Air Quality Index (AQI), has been automatically implemented using sensors data and compared to the referenced data of the city air monitoring stations in order to address the Indicative Measurements of the Ambient Air Quality EU Directive and Cleaner Air for Europe (2008/50/EC).

A typical map of AQI using the sensor network data from the stationary nodes (e.g., airport, port, city office, factories, university, etc.) and mobile node (mounted on city public bus) has been reported in the city of Bari.

The RES-NOVAE Consortium (2011-2015) has been leaded by ENEA with partners such as large companies (ENEL, project manager, IBM, GE), small companies (Asperience, Tera), academia (Technical University of Bari, University of Calabria) and research (CNR, ENEA). A strong support from Municipalities of Bari and Cosenza has been received as public end-user of the final output (products and services) of the national project.

\section{The AIRBOX sensor-system}

In ENEA, at Brindisi Research Center, a gas sensor-system, called AIRBOX, based on lowcost gas sensors has been realized [8-16]. The sensor-system AIRBOX is equipped with 4 lowcost electrochemical gas sensors $\left(\mathrm{NO}_{2}, \mathrm{O}_{3}, \mathrm{CO}\right.$, $\left.\mathrm{SO}_{2}\right), 1$ NDIR sensor $\left(\mathrm{CO}_{2}\right)$ and 1 PhotoIonisation detector (tVOCs) by Alphasense Ltd (UK), 1 low-cost optical PM detector by Shinyei Technology Co Ltd (Japan), 1 temperature sensor (LM35CZ) by National Semiconductor Co. (USA), and 1 relative humidity sensor $(\mathrm{HIH}-$ 3610 Series) by Honeywell (USA). The characteristics of the sensors for air quality monitoring are reported in the Table 2.

Tab. 2: Characteristics of AIRBOX sensors.

\begin{tabular}{|c|c|c|c|}
\hline \multirow[b]{2}{*}{ Gas } & \multicolumn{3}{|c|}{ Sensor Features } \\
\hline & $\begin{array}{c}\text { Model / } \\
\text { Manufacturer }\end{array}$ & $\begin{array}{c}\text { Operating } \\
\text { range }(p p m)\end{array}$ & Size $(\mathrm{mm})$ \\
\hline $\mathrm{NO}_{2}$ & $\begin{array}{l}\text { NO2A1 - B4 } \\
\text { Alphasense }\end{array}$ & $0-2$ & Diameter: 20 \\
\hline $\mathrm{O}_{3}$ & $\begin{array}{l}\text { O3A1 - B4 } \\
\text { Alphasense }\end{array}$ & $0-2$ & Diameter: 20 \\
\hline $\mathrm{CO}$ & $\begin{array}{l}\text { COCX - B4 } \\
\text { Alphasense }\end{array}$ & $0-20$ & Diameter: 20 \\
\hline $\mathrm{SO}_{2}$ & $\begin{array}{l}\text { SO2AF - B4 } \\
\text { Alphasense }\end{array}$ & $0-2$ & Diameter: 20 \\
\hline $\mathrm{CO}_{2}$ & $\begin{array}{l}\text { CO2 - NDIR } \\
\text { Alphasense }\end{array}$ & $0-3000$ & Diameter: 20 \\
\hline tVOCs & $\begin{array}{l}\text { VOCs-PID } \\
\text { Alphasense }\end{array}$ & $0-100$ & Diameter: 20 \\
\hline PM & $\begin{array}{l}\text { PPD20V } \\
\text { Shinvey }\end{array}$ & $\begin{array}{c}\text { Particle size: } \\
\text { 1-5 } \mu \mathrm{m} ; \\
\text { Range: } \\
0 \text { - } 100 \mu \mathrm{g} / \mathrm{m}^{3}\end{array}$ & $59 \times 45 \times 22$ \\
\hline Temp & $\begin{array}{c}\text { LM35CZ } \\
\text { National } \\
\text { Semiconductor }\end{array}$ & $-10^{\circ} \mathrm{C}-+80^{\circ} \mathrm{C}$ & $8 \times 5 \times 2$ \\
\hline $\mathrm{RH}$ & $\begin{array}{c}\mathrm{HIH}-3610 \\
\text { Honeywell }\end{array}$ & $0-90 \%$ & $6 \times 6 \times 2$ \\
\hline
\end{tabular}

AIRBOX has a high flexibility grade with several designed modules: main board, sensor boards, USB port-hub, power module, GSM modem, GPS device. The main board is a Raspberry PI module to interface the end-user with the sensor boards providing smart functionalities. The sensor boards communicate with main module via USB port-hub in master-slave scheme. The end-user interface is given by a web browser for remote control. The low-cost sensor-system is shown in the Fig. 1. The AIRBOX sensor-nodes distributed in the Bari (Italy) are shown in Fig. 2.

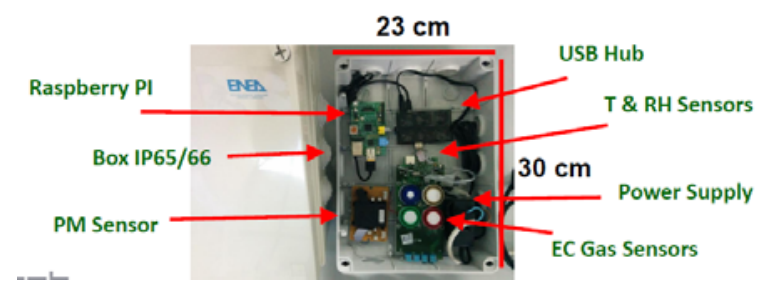

Fig. 1. AIRBOX sensor-system by ENEA (Brindisi) for air quality monitoring as node distributed in city. 


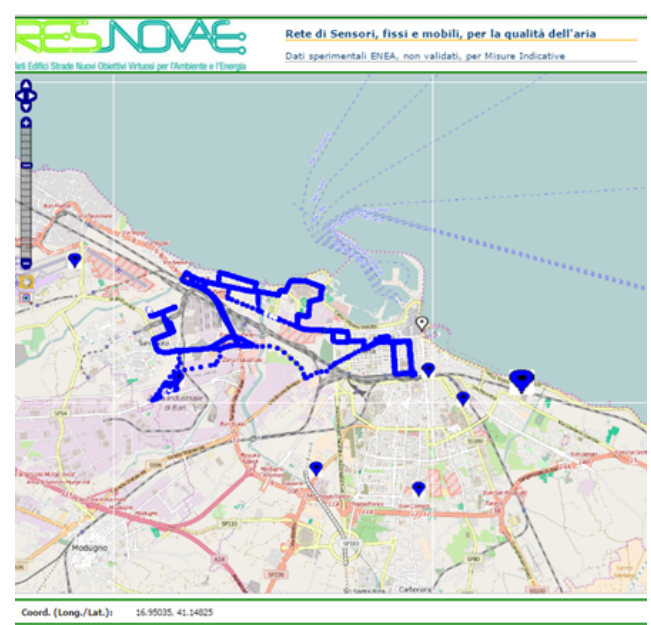

ENEA Sensors Lab OpenVPN Status Monitor

\begin{tabular}{|c|c|c|c|c|c|c|c|c|c|}
\hline & & & & & & & & & \\
\hline 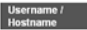 & $\begin{array}{l}\text { YondP } \\
\text { Address }\end{array}$ & $\begin{array}{l}\text { Rempoterp } \\
\text { hadtess }\end{array}$ & Port & Location & Reev & Sent & Connected Snce & Last Ping & Time Ontine \\
\hline nasusoits & 172170.6 & 37.19 .10820 & 52428 & 드 & 73065 & 73872 & $\begin{array}{c}230222016 \\
1528090\end{array}$ & $\begin{array}{c}230222016 \\
1522816\end{array}$ & $301: 40$ \\
\hline nasusson:8 & 17217.09 & 62.19 .56 .54 & 20059 & $\mathbf{U}$ & 16932314 & 8252487 & $\begin{array}{l}1400222016 \\
0200633\end{array}$ & $\begin{array}{c}2300222016 \\
182623\end{array}$ & 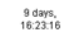 \\
\hline nasusot.2 & 172.17 .0 .3 & 62:19.60.187 & 50059 & $\mathbf{u}$ & 61118723 & 29838611 & $\begin{array}{l}1900122016 \\
1533129\end{array}$ & $\begin{array}{c}2300222016 \\
182213\end{array}$ & 管 \\
\hline nasuset 12 & 17217.013 & 5.170 .133 .155 & 21548 & $\boldsymbol{u}$ & 3988071 & 2173688 & $\begin{array}{r}2200222016 \\
123111\end{array}$ & $\begin{array}{c}2300222016 \\
1826445\end{array}$ & $1 \mathrm{dar}, 558.38$ \\
\hline nasusol 3 & 17217.0 .4 & 5.170 .159 .2113 & 49326 & $\mathbf{u}$ & 50720954 & 24762444 & $\begin{array}{r}2500129016 \\
145929\end{array}$ & $\begin{array}{c}230202201016 \\
1818.48\end{array}$ & 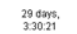 \\
\hline nasusont 13 & 17217.014 & 6219.60 .37 & 20028 & $\mathbf{u}$ & 10410073 & 4378176 & $\begin{array}{l}1900222016 \\
152235 \\
15235\end{array}$ & $\begin{array}{l}230225216 \\
18194949\end{array}$ & 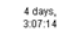 \\
\hline nasusant-6 & 172170.7 & $5.170 .100 \cdot 125$ & 44309 & U & 60155115 & 28671705 & $\begin{array}{l}210172016 \\
0033505\end{array}$ & $\begin{array}{l}230225216 \\
1827228\end{array}$ & 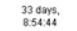 \\
\hline aibowene & 17217.020 & 192.166.172238 & 30932 & RfC1918 & 2992201 & 3165714 & $\begin{array}{l}180222016 \\
0920228\end{array}$ & $\begin{array}{l}180222016 \\
0920228\end{array}$ & $\underset{\substack{5 \text { domp. } \\
900921}}{ }$ \\
\hline nassosol-1 1 & 17217.02 & 6219.59 .82 & 13710 & $\|$ & 16893240 & 8246839 & $\begin{array}{l}1400222016 \\
0200549\end{array}$ & $\begin{array}{l}230022016 \\
1817.56\end{array}$ & 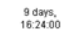 \\
\hline nassuset? & 17217.010 & 6219.59 .173 & 34552 & U & 9107149 & 4258171 & 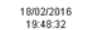 & $\begin{array}{l}230222016 \\
182632.32\end{array}$ & 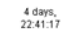 \\
\hline nasusoit 4 & 17217.0 .5 & 62.1957 .93 & 34803 & $\|$ & 25405566 & 12317796 & $\begin{array}{l}0902222016 \\
060273737\end{array}$ & $\begin{array}{l}230225216 \\
1825551\end{array}$ & 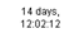 \\
\hline nasusot 10 & 17217.011 & 5.170 .246 .120 & 20180 & $\mathbf{u}$ & 17262918 & 8314106 & $\begin{array}{c}1400225016 \\
00202577\end{array}$ & $\begin{array}{l}23020222016 \\
181810\end{array}$ & 9 \\
\hline
\end{tabular}

Fig. 2. Map and VPN of the AQ sensor network at Bari (Italy) in the frame of RES-NOVAE [7].

\section{Results}

Currently, a long-term experimental campaign (June 2015 - Dec 2016) is running in Bari to assess sensor performance in real scenario.

\section{CO detection}

Fig. 3 shows the Air Quality Index (AQI) measured by the AIRBOX installed in node 2 (ENEA Office) and node 6 (Airport) using the electrochemical $\mathrm{CO}$ sensor compared to reference method by official air quality station closest to the sensor node.
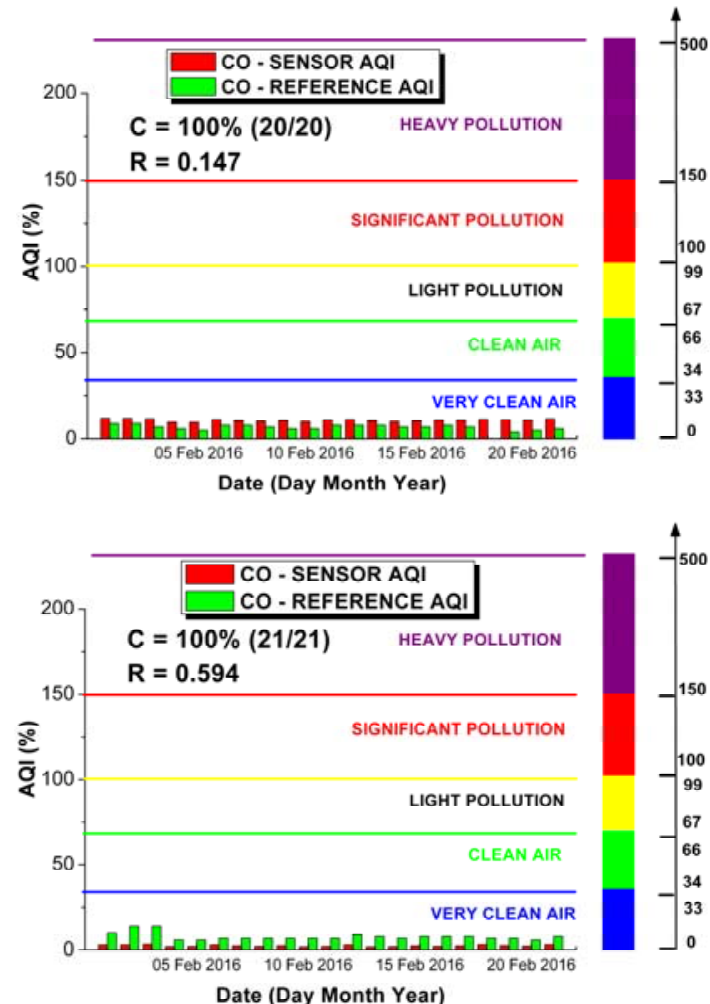

Fig. 3. Air Quality Index (AQI) of CO measured by reference analyzer and AIRBOX sensor-system operated at Node 2 - ENEA HQ (top) and Node 6 . Bari Airport (bottom) on February 2016.
The Classification Index (C) is $100 \%$ to classify the AQI measured by CO sensor compared to reference method. The Correlation Coefficient (R) ranges from 0.147 (node 2) to 0.594 (node 6) depending on local conditions.

\section{$\mathrm{O}_{3}$ detection}

Fig. 4 shows the Air Quality Index (AQI) measured by the AIRBOX installed in node 6 (Airport) using the electrochemical $\mathrm{O}_{3}$ sensor compared to reference method by official air quality station closest to the sensor node.

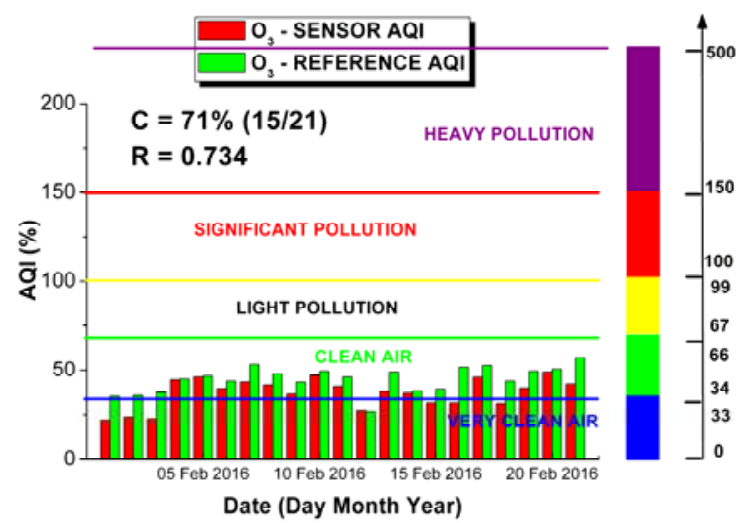

Fig. 4. Air Quality Index (AQI) of $\mathrm{O}_{3}$ measured by reference analyzer and AIRBOX sensor-system operated at Node 6 - Bari Airport on February 2016.

The Classification Index (C) is $71 \%$ to classify the AQI measured by $\mathrm{O}_{3}$ sensor compared to reference method. The Correlation Coefficient $(R)$ is estimated as 0.734 (node 6).

$P M_{10}$ detection

Fig. 5 shows the Air Quality Index (AQI) measured by the AIRBOX installed in node 2 (ENEA Office) and node 6 (Airport) using the optical PM sensor compared to reference method by official air quality station closest to the sensor node. 

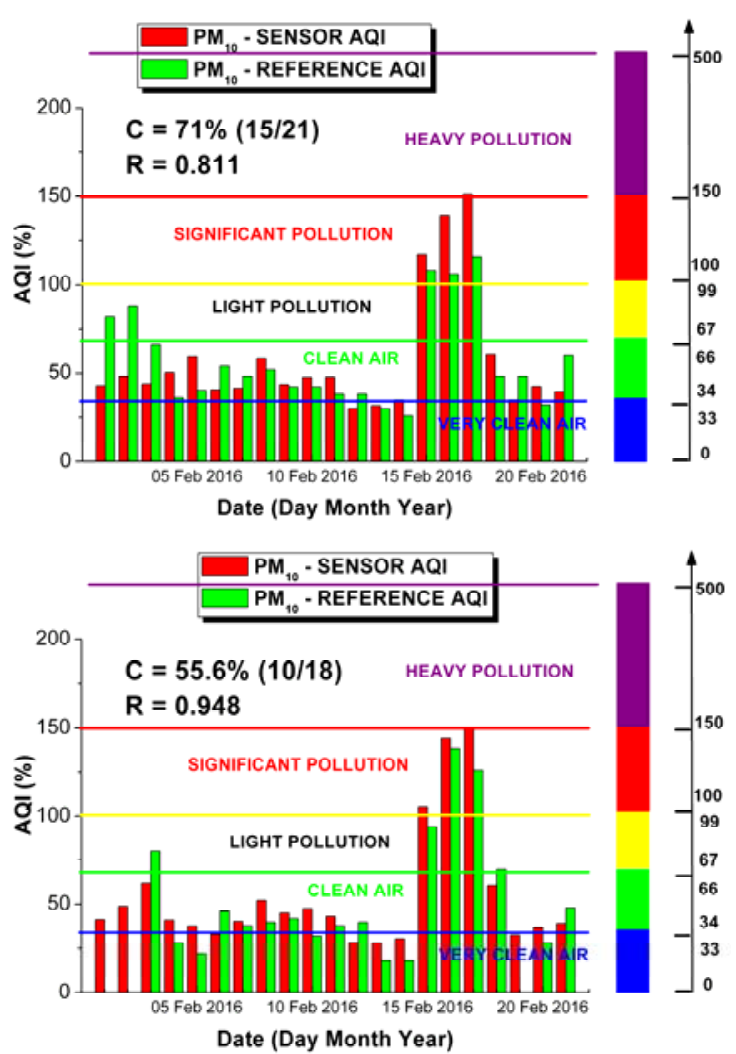

Fig. 5. Air Quality Index (AQI) of $P M_{10}$ measured by reference analyzer and AIRBOX sensor-system operated at Node 2 - ENEA HQ (top) and Node 6 Bari Airport (bottom) on February 2016.

The Classification Index (C) ranges from $71 \%$ (node 2) to $55.6 \%$ (node 6) to classify the AQI measured by $\mathrm{PM}$ sensor compared to reference method. The Correlation Coefficient $(R)$ ranges from 0.811 (node 2) to 0.948 (node 6) depending on local conditions. The $\mathrm{PM}_{10}$ exceedance recorded by sensors on 15, 16 and 17 February 2016 is due to Saharian dust, as certified by the local environmental authority.

\section{Conclusion and outlook}

These preliminary results achieved within the national project for the city $\mathrm{AQ}$ monitoring by low-cost sensors are very promising. Of course, to achieve the overall goal of low-cost monitoring and accurate measurements, many problems remain to be solved, e.g. regular calibration, elimination of cross-interference, drift correction, enhanced selectivity to make full use of the potential provided by the low-cost sensor-systems for large involvement of the citizens in the air quality monitoring [17].

\section{Acknowledgements}

This work has been partially funded by national RES-NOVAE project (grant agreement No. PON4a2_E) from Italian Ministry of University, Research and High Schools. The authors are strongly indebted to the COST Action TD1105
EuNetAir (2012-2016), which has provided valuable inputs through networking activities.

\section{References}

[1] EU Air Quality Directive 2008/50/EC (http://ec.europa.eu/environment/air/quality/legislation/e xisting_leg.htm)

[2] F.J. Kelly, G.W. Fuller, H.A. Walton, and J.C. Fussell Monitoring air pollution: use of early warning systems for public health, Respirology, 17, 7-19 (2012).

[3] M. Aleixandre and M. Gerboles, Review of small commercial sensors for indicative monitoring of ambient gas,Chemical Engineering Transactions, 30, 169-174 (2012).

[4] A.R. Al-Ali, I. Zualkernan, and F. Aloul, A mobile GPRSsensors array for air pollution monitoring, IEEE Sensors Journal, 10 (10), 1666-1671 (2010).

[5] D. Hasenfratz, O. Saukh, S. Sturzenegger, and L. Thiele, Participatory air pollution monitoring using smartphones, The $2^{\text {nd }}$ International Workshop on Mobile Sensing, April 16-20, 2012, Beijing, China. 2012 ACM 978-1-4503-1227-1/12/04.

[6] C. Borrego et al., Assessment of air quality microsensors versus reference methods: The EuNetAir joint exercise, Atmospheric Environment 147 (2016) 246-263.

[7] http:// http://resnovae-unical.it/ricerca-1-bozza/

[8] M. Penza et al., COST Action TD1105: European Network on New Sensing Technologies for Air pollution Control and Environmental Sustainability, Linkoping EuNetAir Meeting, AMA Science 2015 Proceedings, Linkoping, Sweden, 3-5 June 2015. DOI 10.5162/EuNetAir2015/15.

[9] European Sensor Systems Cluster (ESSC): www.cluster-essc.eu

[10] M. Penza et al., The European Sensor Systems Cluster - ESSC: A New EC Initiative, Linkoping EuNetAir Meeting, AMA Science 2015 Proceedings, Linkoping, Sweden, 3-5 June 2015.

[11] COST Action TD1105 EuNetAir webpages: www.cost.eunetair.it

[12] COST Action TD1105 EuNetAir ESSEM http://www.cost.eu/domains_actions/essem/Actions/TD 1105

[13] M. Penza, COST Action TD1105: Overview of SensorSystems for Air Quality Monitoring, Procedia Engineering 87 (2014) 1370-1377.

[14] M. Penza et al., COST Action TD1105: New Sensing Technologies for Environmental Sustainability in Smart Cities, IEEE Sensors 2014 Proceedings, Valencia, Spain, 2-5 Nov. 2014. DOI: 978-1-4799-01623/14§31.00@2014 IEEE.

[15] M. Penza, Portable Sensor-Systems for Air Quality Monitoring: The Case-Study of EuNetAir, 2nd Meeting of the Global Platform on Air Quality and Health, Geneva, Switzerland, 18-20 August 2015.

[16] M. Penza, COST Action TD1105: European Network on New Sensing Technologies for Air Pollution Control and Environmental Sustainability. Overview and Plans, Procedia Engineering 120 (2015) 476-479.

[17] US EPA Draft Roadmap on Next Generation of Air Monitoring (NGAM): http://epa.gov/research/airscience/docs/roadmap20130308.pdf 